\title{
ANTIOXIDANT, ANTI-LIPID PEROXIDATIVE AND ANTIMICROBIAL PROPERTIES OF THE EPIPHYTIC FERN, PYRROSIA HETEROPHYLLA (L.) M. G. PRICE
}

\author{
MEERA GEORGE, LEENAMMA JOSEPH, V. S. JOSEKUMAR* \\ Department of Zoology, Mar Ivanios College (Autonomous), Thiruvananthapuram 695015, Kerala, India \\ Email: vsjosekumar@gmail.com
}

Received: 28 Dec 2016 Revised and Accepted: 14 Feb 2017

\begin{abstract}
Objective: The present study was aimed at establishing the antioxidant, free radical scavenging, anti-lipid peroxidative and antimicrobial properties of the plant Pyrrosia heterophylla (L.) M. G. PRICE.

Methods: Standard protocols were used to estimate the antioxidant potential of the hexane, ethyl acetate and methanolic extracts of the plant. Radical scavenging ability of the extracts was assayed for 2, 2'-azino-bis (3-ethylbenzothiazoline-6-sulphonicacid) (ABTS), 1,1-diphenyl-2-picrylhydrazil (DPPH) and hydroxyl radicals. Total antioxidant activity assay was done following the phospho- molybdenum method. The reductive potential was measured by ferric reducing antioxidant power (FRAP) assay. Lipid peroxidation assay was done in vitro. Total phenolic content was measured by the Folin-Ciocalteu method. Antimicrobial activity was identified by well diffusion method, and minimum inhibitory concentration (MIC) was determined by serial dilution method.
\end{abstract}

Results: Results revealed that the ethyl acetate extract (PHE) exhibited the highest antioxidant capacity followed by the methanolic extract (PHM) whereas the hexane extract (PHH) had the lowest activity. The percentage radical scavenging by PHE was found to be $86.63 \pm 0.85,89.48 \pm 2.08$ and $70.89 \pm 1.46$ for DPPH, ABTS and hydroxyl radicals respectively, at a concentration of $800 \mu \mathrm{g} / \mathrm{ml}$. The total antioxidant activity of PHE, PHM and PHH was found to be $538.33 \pm 3.51,283.33 \pm 7.57$ and $13.76 \pm 3.95$ ascorbic acid equivalents/g of extract respectively. Phenolic content of PHE was the highest (207.22 \pm 1.95 gallic acid equivalents (GAE)/g of extract), followed by PHM and PHH (197.92 \pm 2.00 and $37.50 \pm 2.18$ GAE/g respectively). Total reducing power was also found to be the highest in PHE followed by PHM and PHH as per the FRAP assay. All the extracts were found to possess inhibitory activity against the tested microorganisms. MIC50 value of all the extracts was below $40 \mu \mathrm{g} / \mathrm{ml}$.

Conclusion: The results of this study confirmed the antioxidant, antimicrobial and anti-lipid peroxidation potentials of the plant $P$. heterophylla (L.) M. G. PRICE.

Keywords: Pyrrosia heterophylla, Epiphytic fern, Antioxidant, Free radical scavenging, Lipid peroxidation, ABTS, DPPH, Antimicrobial

(c) 2017 The Authors. Published by Innovare Academic Sciences Pvt Ltd. This is an open access article under the CC BY license (http://creativecommons.org/licenses/by/4.0/) DOI: http://dx.doi.org/10.22159/ijpps.2017v9i4.16827

\section{INTRODUCTION}

Free radicals are generated during oxidative phosphorylation, as a byproduct in mitochondria. These radicals have some beneficial role in the body especially in cell signalling and immune responses. However, at higher concentrations, these radicals cause oxidative stress which is a deleterious process that can damage the cell structures. The delicate balance between the beneficial and harmful effects of free radicals is an important aspect that helps to maintain the health of biological systems [1-5]. Free radicals can inactivate enzyme systems and damage cellular components by covalent binding and lipid peroxidation. Lipid peroxidation has been implicated in the pathogenesis of a number of clinical conditions like Parkinson's disease, Alzheimer's disease, chronic inflammatory conditions, atherosclerosis, fibrosis, inflammatory liver injury, type I diabetes, etc. $[1,6]$

The body has several mechanisms to reduce oxidative stress. It is achieved either by producing antioxidants naturally within the body or by supplying externally through foods. The role of antioxidants is to neutralize the excess of free radicals generated and protect the cells against their toxic effects [7]. Antioxidants have been defined by Halliwell [1] as "any substance that when present at low concentrations with those of an oxidizable substrate significantly delays or prevents oxidation of that substrate."

Antioxidants from our diet or other supplements help the endogenous antioxidants for the neutralisation of oxidative stress. Natural antioxidants like phenolics and flavonoids present in tea, wine, fruits, vegetables and spices are already exploited commercially either as antioxidant additives or as nutritional supplements [8]. There is still demand to find more information concerning the antioxidant potential of plant species as they are safe and also bioactive. Therefore, in recent years, considerable research has been targeted towards the identification of new plants with antioxidant ability.

Conventional antibiotics used in the treatment of infectious diseases are found to have many side effects [9]. Moreover development of resistant strains of pathogenic microorganisms is a serious issue in clinical practice. Present researches are more focused on drugs with minimum side effects. Development of new antimicrobial agents from plant secondary metabolites is a new approach since their side effects are lesser when compared to their synthetic chemical counterparts [10].

There is always a need for the plants used in traditional medicine to be scientifically evaluated for their bioactivities. Study of the antioxidant properties of a plant is an essential aspect of bio prospecting; as this will help to understand the possibility of isolating new bioactive compounds from these plants. Pyrossia heterophylla (syn Drymoglossum heterophyllum (L.) C. Chr, Acrostichum heterophyllum L.) is an epiphytic fern of the family Polypodiaceae. Traditionally the plant has been used in treatments of asthma, swellings, pain, sprains, etc. [11]. Our earlier investigation had proved the plant to be a rich source of phenolic compounds, saponins and flavonoids [12]. The traditional use of the plant is not yet scientifically authenticated. Thus the present study was targeted at exploring the antioxidant, antimicrobial, free radical scavenging and anti-lipid peroxidative activities of three successive extracts of this plant.

\section{MATERIALS AND METHODS}

Chemicals

1, 1-diphenyl-2-picryl-hydrazil (DPPH) and 2,2'-azino-bis(3- 
ethylbenzothiazoline-6-sulphonic acid) (ABTS) was purchased from Sigma Aldrich India. Other chemicals, sodium carbonate, sodium phosphate, potassium ferricyanide, ammonium molybdate,, ascorbic acid, gallic acid, 2-thiobarbituric acid (TBA), trichloroacetic acid, Folin-Ciocalteu reagent, 2-deoxyribose and $\mathrm{H}_{2} \mathrm{O}_{2}(30 \%, \mathrm{v} / \mathrm{v})$ and media for antimicrobial studies were from Merck India Ltd and Himedia, Mumbai, India. All other chemicals and solvents used were of analytical grade.

\section{Microbial strains}

Gram-negative strains like Escherichia coli (ATCC 25922), Klebsiella pneumonia (ATCC 13883), Pseudomonas aeruginosa (ATCC 27853) and gram-positive strains like Streptococcus mutans (MTCC 890) and Staphylococcus aureus (ATCC 25923) were used for studying antibacterial activity. For the antifungal studies, two strains namely Candida albicans (ATCC 10231) and Aspergillus niger (ATCC 16404) were used. American type culture collection (ATCC) strains were purchased from Himedia, Mumbai while Streptococcus mutans was obtained from Institute of Microbial Technology (IMTECH), Chandigarh, India.

\section{Collection and extraction of plant material}

Fresh plant material was collected from local sources and authenticated by Dr. G. Valsaladevi, Department of Botany, University of Kerala, Thiruvananthapuram, Kerala and a voucher specimen (No. KUBH 5926) was deposited in the herbarium of the same department. The leaves were washed with distilled water, dried in a hot air oven $\left(40^{\circ} \mathrm{C}\right)$ and powdered. The leaf powder was sequentially extracted in hexane (PHH), ethyl acetate (PHE) and methanol (PHM) in a soxhlet apparatus. Extraction was continued until the solvent in the sample holder became colourless. The temperature was set not to exceed the boiling point of the solvent. Each extract was concentrated in a rotary vacuum evaporator and the concentrated extracts were stored below $0{ }^{\circ} \mathrm{C}$ till further analysis.

\section{DPPH radical scavenging activity}

DPPH radical scavenging activity was measured according to the protocol of Blois [13] with slight modifications. $2.5 \mathrm{ml}$ of DPPH solution $(0.003 \%$ in $70 \%$ methanol) was incubated with $0.5 \mathrm{ml}$ of the extract at different concentrations $(50,100,200,400$ and 800 $\mu \mathrm{g} / \mathrm{ml}$ ). The reaction mixture was shaken well and incubated in the dark for $30 \mathrm{~min}$ at room temperature. Control was prepared as above with $0.5 \mathrm{ml}$ methanol instead of the extract. The absorbance of the solution was measured at $517 \mathrm{~nm}$ against a reagent blank. The radical scavenging activity was measured as a decrease in absorbance of DPPH. All the tests were run in triplicate. Ascorbic acid was used as a standard. The percentage scavenging activity is calculated as

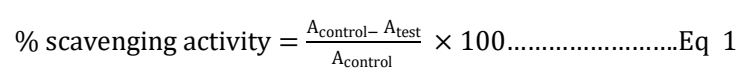

\section{ABTS radical scavenging assay}

The antioxidant capacity in terms of the ABTS radical scavenging activity was estimated following the procedure described by Delgado-Andrade et al. [14]. Briefly, ABTS ${ }^{\bullet}$ was obtained by reacting $7 \mathrm{mmol}$ ABTS stock solution with $2.45 \mathrm{mmol}$ potassium persulfate and the mixture was left to stand in the dark at room temperature for 12-16 h before use. The ABTS ${ }^{\bullet+}$ solution was diluted with $5 \mathrm{mmol}$ phosphate-buffered saline ( $\mathrm{pH} 7.4$ ) to an absorbance of $0.70 \pm 0.02$ at $730 \mathrm{~nm}$. After the addition of $30 \mu \mathrm{L}$ of sample to $3 \mathrm{ml}$ of diluted ABTS ${ }^{\bullet}$ solution, the absorbance was measured after $30 \mathrm{~min}$. All samples were analyzed in triplicate. Percentage scavenging ability was calculated as per the equation 1.

\section{Hydroxyl radical scavenging assay}

The hydroxyl radical scavenging activity of the plant extracts was measured by the deoxyribose method [15] and compared with that of butylated hydroxytoluene (BHT). The reaction mixture containing plant extracts (final concentration 50-800 $\mu \mathrm{g} / \mathrm{ml}$ ), deoxyribose ( $3.75 \mathrm{mmol}), \mathrm{H}_{2} \mathrm{O}_{2}(1 \mathrm{mmol})$, potassium phosphate buffer $(20 \mathrm{mmol}$, $\mathrm{pH} 7.4), \mathrm{FeCl}_{3}(0.1 \mathrm{mmol})$, EDTA $(0.1 \mathrm{mmol})$ and ascorbic acid (0.1 mmol) were incubated in a water bath at $37 \pm 0.5^{\circ} \mathrm{C}$ for 1 hour. The extent of deoxyribose degradation was measured by the TBA method [16]. All the analyses were done in triplicates and average values were taken. Inhibition of deoxyribose degradation in percentage was calculated according to the equation 1 .

\section{Lipid peroxidation inhibition assay}

The effect of the different concentrations of $P$. heterophylla extracts on $\mathrm{Fe}^{2+}$ /Ascorbate-induced lipid peroxidation in sheep liver homogenate was assessed by the method of Okhava et al. [16] with modifications. The reaction mixture contained $1 \mathrm{ml}$ tissue homogenate ( $10 \%$ in $1 \%$ ice cold $\mathrm{KCl}$ ), $0.1 \mathrm{ml} \mathrm{FeSO} 4$ ( $15 \mathrm{mmol}$ ), 0.1 $\mathrm{ml}$ ascorbic acid ( $0.2 \mathrm{mmol})$ and $1 \mathrm{ml} \mathrm{KH}_{2} \mathrm{PO}_{4}$. The volume was made up to $3 \mathrm{ml}$ with distilled water. The mixture was incubated for 45 min at $37{ }^{\circ} \mathrm{C}$. Test systems contained different concentrations of the extracts $(50,100,200,400$ and $800 \mu \mathrm{g} / \mathrm{ml})$. The reaction was stopped by the addition of $1 \mathrm{ml}$ of $10 \%$ trichloroacetic acid (TCA). The tubes were shaken well and centrifuged at $3000 \mathrm{rpm}$ for $10 \mathrm{~min}$. $2 \mathrm{ml}$ of the supernatant was taken and $1.5 \mathrm{ml}$ of $0.6 \%$ TBA was added. The mixture was heated in a water bath at $90{ }^{\circ} \mathrm{C}$ for $30 \mathrm{~min}$. The intensity of the pink coloured complex was measured at 535 nm. Percentage of lipid peroxidation inhibition was calculated as per equation 1 . The experiments were done in triplicates and ascorbic acid was used as the standard.

\section{Ferric ions $\left(\mathrm{Fe}^{3+}\right)$ reducing antioxidant power assay (FRAP)}

The reducing power of the extracts was determined by the method of Oyaizu [17]. $1 \mathrm{ml}$ of plant extract at various concentrations (50$800 \mu \mathrm{g} / \mathrm{ml}$ ) was mixed with $2.5 \mathrm{ml}$ of sodium phosphate buffer (0.2M, pH 6.6) and $2.5 \mathrm{ml}$ of potassium ferricyanide (1\%). The mixture was incubated at $50^{\circ} \mathrm{C}$ for $20 \mathrm{~min}$. To this, $2.5 \mathrm{ml}$ of trichloroacetic acid (10\%) was added and centrifuged at $3000 \mathrm{rpm}$ for $10 \mathrm{~min}$. The upper layer of the solution $(2.5 \mathrm{ml})$ was mixed with $2.5 \mathrm{ml}$ of distilled water and $0.5 \mathrm{ml}$ of ferric chloride $(0.1 \%)$. Absorbance was measured at $700 \mathrm{~nm}$. Increased absorbance indicates higher reducing power.

\section{Total antioxidant capacity}

Total antioxidant capacity was determined by the phosphomolybdenum method as described by Kannan et al. [18]. $0.3 \mathrm{ml}$ of plant extract at different concentrations was mixed with $3 \mathrm{ml}$ of phospho- molybdenum reagent $(28 \mathrm{mmol}$ sodium phosphate and 4 mmol ammonium molybdate in $0.6 \mathrm{M}$ sulfuric acid). The tubes were incubated at $95^{\circ} \mathrm{C}$ for $90 \mathrm{~min}$. Cooled and the absorbance was read at $695 \mathrm{~nm}$, against reagent blank. Ascorbic acid was used as the standard. The total antioxidant activity was expressed as ascorbic acid equivalents (AAE) per gram of extract.

\section{Estimation of total phenolic content}

The total phenolic content of the extracts was determined by the Folin-Ciocalteu method [19] with slight modifications. $0.5 \mathrm{ml}$ of plant extract is mixed with $2.5 \mathrm{ml}$ of $10 \%$ Folin-Ciocalteu reagent and $2.5 \mathrm{ml}$ of $7.5 \%$ sodium carbonate. The mixture is incubated at room temperature for $30 \mathrm{~min}$ and the absorbance is read at $765 \mathrm{~nm}$. Gallic acid was used as a standard. Phenolic content was expressed as gallic acid equivalents (GAE) per gram of extract.

\section{Antibacterial activity by well diffusion assay}

Preliminary screening of antibacterial activity was performed by the well diffusion method. Antibacterial activity was determined on the basis of a clear zone formed around the well. Petri plates containing $20 \mathrm{ml}$ Muller Hinton Agar Medium were seeded with the bacterial culture of Klebsiella pneumoniae, Pseudomonas aeruginosa, Streptococcus mutans, Escherichia coli and Staphylococcus aureus (growth of culture adjusted according to McFards Standard, 0.5\%). Wells of approximately $10 \mathrm{~mm}$ diameter were bored using a well cutter and 25,50 , and $100 \mu \mathrm{g} / \mathrm{ml}$ of plant extracts (in $0.1 \%$ DMSO) were added. The plates were then incubated at $37^{\circ} \mathrm{C}$ for $24 \mathrm{~h}$. The antibacterial activity was assayed by measuring the diameter of the inhibition zone formed around the well [20]. Streptomycin was used as a reference drug and $0.1 \%$ DMSO was used as a negative control. All tests were done in triplicates and antibacterial activity was expressed as the mean value of inhibition zone $(\mathrm{mm})$. 


\section{Antifungal activity}

Antifungal activity was determined by agar well diffusion method. Potato dextrose agar plates were prepared. Two different species of fungi such as Candida albicans and Aspergillus niger were swabbed. Wells of approximately $10 \mathrm{~mm}$ diameter were bored using a well cutter and 25,50 , and $100 \mu \mathrm{g} / \mathrm{ml}$ of plant extract (in $0.1 \%$ DMSO) were added.

The plates were then incubated at $37{ }^{\circ} \mathrm{C}$ for $24 \mathrm{~h}$. The antifungal activity was assessed by measuring the diameter of the inhibition zone formed around the well [20]. Clotrimazole was used as a reference drug and $0.1 \%$ DMSO was used as a negative control. All tests were done in triplicates and antifungal activity was expressed as the mean of inhibition zone ( $\mathrm{mm}$ ).

\section{Minimum inhibitory concentration (MIC) of plant extracts}

Minimum inhibitory concentration of the extracts was determined by the NCCLS broth microdilution method [20]. It was performed in 96-well microtiter plates. Standardized suspensions of the test organisms (Klebsiella pneumonia, Pseudomonas aeruginosa, Streptococcus mutans, Escherichia coli, Staphylococcus aureus, Candida albicans, and Aspergillusniger) were inoculated into 96-well microtitre plate. A growth control and a sterile control were also kept. Samples were dissolved in $0.1 \%$ DMSO and increasing concentrations were applied in wells $(5,10,15,20,25$ and 30 $\mu \mathrm{g} / \mathrm{ml}$ ) and incubated at $37^{\circ} \mathrm{C}$ for $24 \mathrm{~h}$. Growth was examined by visual inspection and measured the optical density (OD) at $630 \mathrm{~nm}$ using a spectrophotometer. The growth inhibition for the test wells at each sample dilution was determined by the formula:

$$
\text { Percent inhibition }=\frac{(\text { ODofcontrol }- \text { ODoftest }) \times 100}{\text { ODofcontrol }}
$$

MICs were calculated as the lowest drug concentrations that resulted in a $50 \%$ reduction in growth compared with that of the drug-free growth control.

\section{Statistical analysis}

The data were expressed as mean \pm SEM of three replicates. The data were subjected to one-way analysis of variance (ANOVA) and differences between means were determined by the Least Significant Difference (LSD) test using the SPSS Statistics 19.0 Inc. Chicago, USA. $\mathrm{EC}_{50}$ values of the extracts for scavenging of different radicals and the $\mathrm{MIC}_{50}$ values were calculated by regression analysis in SPSS.

\section{RESULTS AND DISCUSSION \\ DPPH radical scavenging activity}

PHE and PHM were found to exhibit significant scavenging of DPPH radicals as shown in fig. 1. Decrease in the absorbance of DPPH radical, resulting in a color change from purple to yellow shows the anti-radical power of the plant extract. The results showed a concentration-dependent reaction and were found to be statistically significant $(\mathrm{p}<0.001)$. PHE exhibited the highest antioxidant capacity in the DPPH radical scavenging assay with $86.63 \pm 0.85 \%$ inhibition at the maximum tested concentration. The $\mathrm{EC}_{50}$ value of PHE was 197. $24 \pm 2.32 \mu \mathrm{g} / \mathrm{ml}$ (table 1 ). The mean percentage inhibition of the three extracts was significantly different from each other $(\mathrm{p}<0.001)$. PHM showed a maximum inhibition of $66.36 \pm 1.05 \%$. PHH was found to have very low inhibitory activity with a maximum inhibition of $7.56 \pm 0.40 \%$. Earlier works have suggested that DPPH scavenging is achieved by an antioxidant by a hydrogen atom transfer process (HAT) [21]. The antioxidant phytochemicals in the extracts work possibly through the donation of hydrogen to form a stable DPPH molecule [22]. Phenolic compounds like gallic acid and flavonoids like epicatechin are shown to exert their antioxidant activity through hydrogen donating mechanism [23]. In the present study, the DPPH radical scavenging achieved by the extracts gives evidence for their ability to donate hydrogen to the radicals.

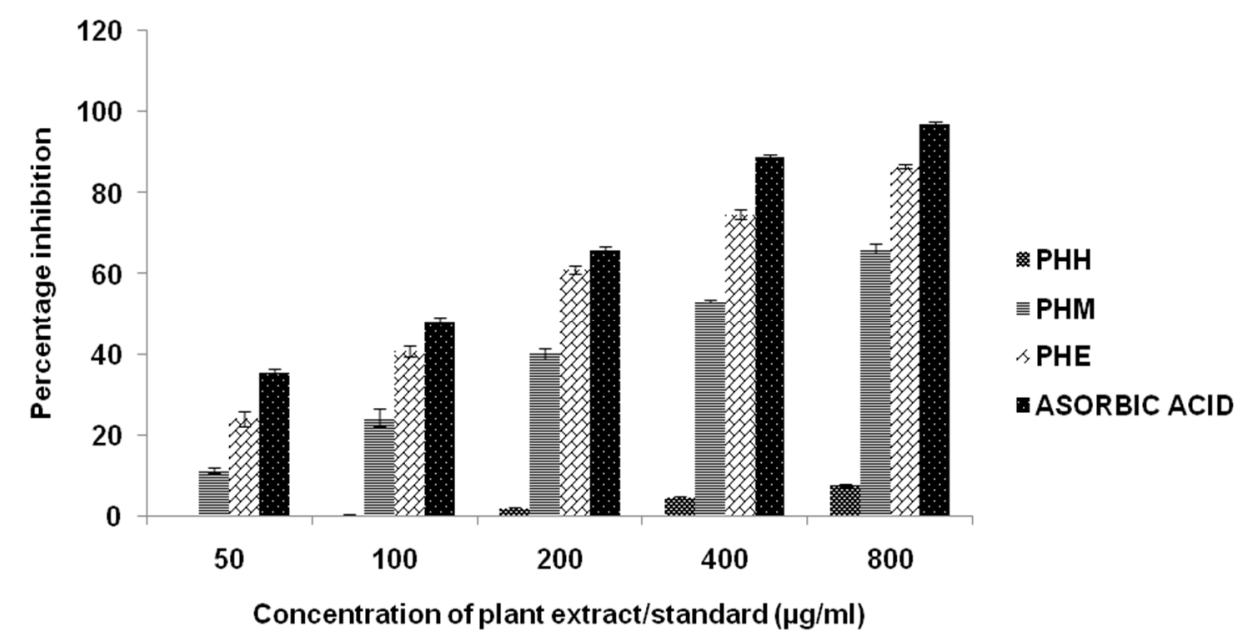

Fig. 1: Scavenging effect of the different extracts of Pyrrosia heterophylla on DPPH radicals. PHH-hexane extract, PHM-methanol extract, PHE-ethyl acetate extract. Values are represented as mean $\pm S E M, n=3$

\section{ABTS radical scavenging assay}

ABTS radicals are generated in the presence of potassium persulfate in the aqueous phase. This assay measures the relative ability of an antioxidant to scavenge the ABTS radicals thus formed. Fig. 2 shows that the highest scavenging was exhibited by PHE (89.48 $2.08 \%)$, followed by PHM (53.25 $\pm 0.86 \%)$. PHH showed very low activity with a maximum inhibition of $9.04 \pm 0.48$.

The mean percentage inhibition of the different extracts was significantly different from each other $(\mathrm{p}<0.001)$. The $\mathrm{EC}_{50}$ value of PHE was found to be $388.80 \pm 1.62$ (table 1). The decrease in absorbance at $730 \mathrm{~nm}$ corresponds to the scavenging ability of the plant extract [24]. Unlike the DPPH radical, ABTS+ radical needs an electron to neutralize its positive charge. The scavenging of $\mathrm{ABTS}^{+}$is therefore considered as an electron transfer reaction [25].

PHE was found to be capable of transferring electrons to $\mathrm{ABTS}^{+}$ radicals thus scavenging them effectively. Earlier studies have shown that flavonoids like kaempferol are found to mediate electron transfer to scavenge free radicals [23]. The effective scavenging of ABTS radicals by the PHE can be attributed to its rich phenolic and flavonoid content. 


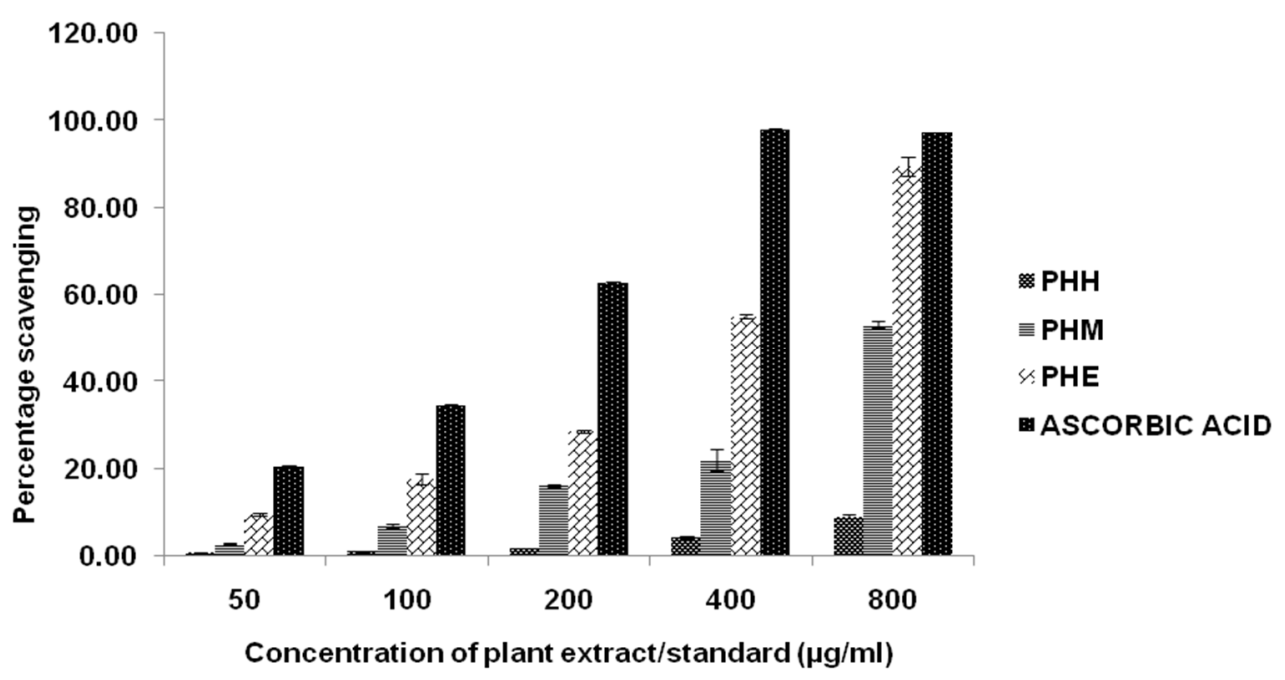

Fig. 2: Scavenging effect of the different extracts of Pyrrosia heterophylla on ABTS radicals. PHH-hexane extract, PHM-methanol extract, PHE-ethyl acetate extract. Values are represented as mean \pm SEM, $n=3$

\section{Hydroxyl radical scavenging}

Ethyl acetate extract was the most effective in scavenging the hydroxyl radicals (fig. 3). It exhibited a maximum inhibition of $70.89 \pm 1.46$ at a concentration of $800 \mu \mathrm{g} / \mathrm{ml}$. All the extracts studied showed a significant difference in mean percentage inhibition from each other $(\mathrm{p}<0.001)$. The maximum level of inhibition by PHM and PHH were $58.33 \pm 0.49 \%$ and $8.82 \pm 0.85 \%$ respectively. Hydroxyl is considered as a highly damaging radical in free radical pathology. It is capable of damaging almost every molecule in living organisms [26]. The results of the hydroxyl scavenging assay is an indicator of the ability of the extracts to quench the reactive oxygen species
(ROS) and the ROS-related chain reactions that may eventually lead to lipid peroxidation, DNA and membrane damages, etc. In the present study, PHE was found to be a promising agent in hydroxyl radical scavenging. Hydroxyl radical scavenging ability of various plant extracts have been reported earlier [27, 28]. Most of the studies correlate this property with the phenolic content of the plants. The present study also suggests a similar effect of plant extracts on hydroxyl radicals. Generation of hydroxyl radicals within the body can lead to lipid peroxidation in biological membranes. The ability of Pyrrosia heterophylla extracts to scavenge hydroxyl radicals can be thus considered as an indicator of its antioxidant activity.

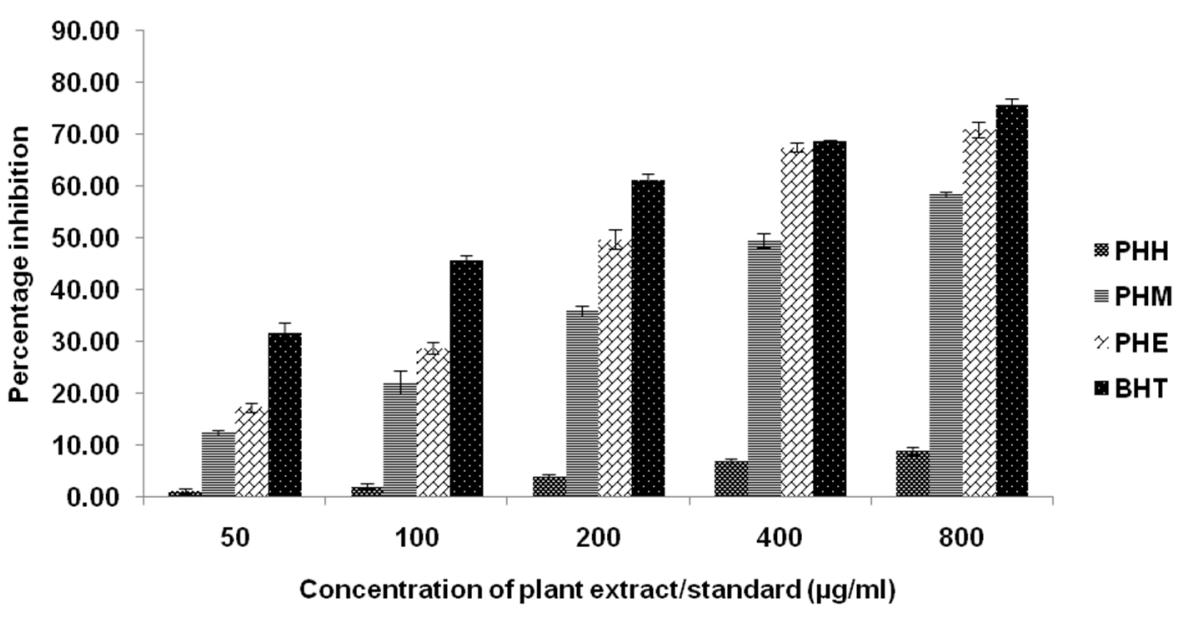

Fig. 3: Scavenging effect of the different extracts of Pyrrosia heterophylla on hydroxyl radicals. PHH-hexane extract, PHM-methanol extract, PHE-ethyl acetate extract, BHT-butylated hydroxyl toluene. Values are represented as mean \pm SEM, $\mathbf{n}=3$

\section{Inhibition of lipid peroxidation by the extracts}

This assay measured the ability of the extracts to inhibit lipid peroxidation in sheep liver homogenate induced by a ferrousascorbate system. Lipid peroxidation is a chain reaction initiated by the hydrogen removal or addition of an oxygen radical, resulting in the oxidative damage of polyunsaturated fatty acids (PUFA). This eventually leads to the formation of a peroxyl radical. The peroxyl radical is capable of abstracting a hydrogen atom from another polyunsaturated fatty acid proceeding with a chain reaction [29]. Among the three extracts, the ethyl acetate extract was found to exert the maximum inhibition on lipid peroxidation (fig. 4). It exhibits a maximum inhibition of $56.12 \pm 1.12 \%$. Methanol and hexane extracts showed an inhibition of $46.74 \pm 0.65 \%$ and $9.12 \pm 0.21 \%$ respectively.

The results of lipid peroxidation inhibition assays indicate the efficiency of the extracts, PHE and PHM, in terminating the chain reaction of lipid peroxidation. This may be due to its ability to scavenge the hydroxyl radicals which have a major role in inducing lipid peroxidation in biological systems [28]. The hydroxyl scavenging activity of the extracts is indicative of the possible protective action against lipid peroxidation. 


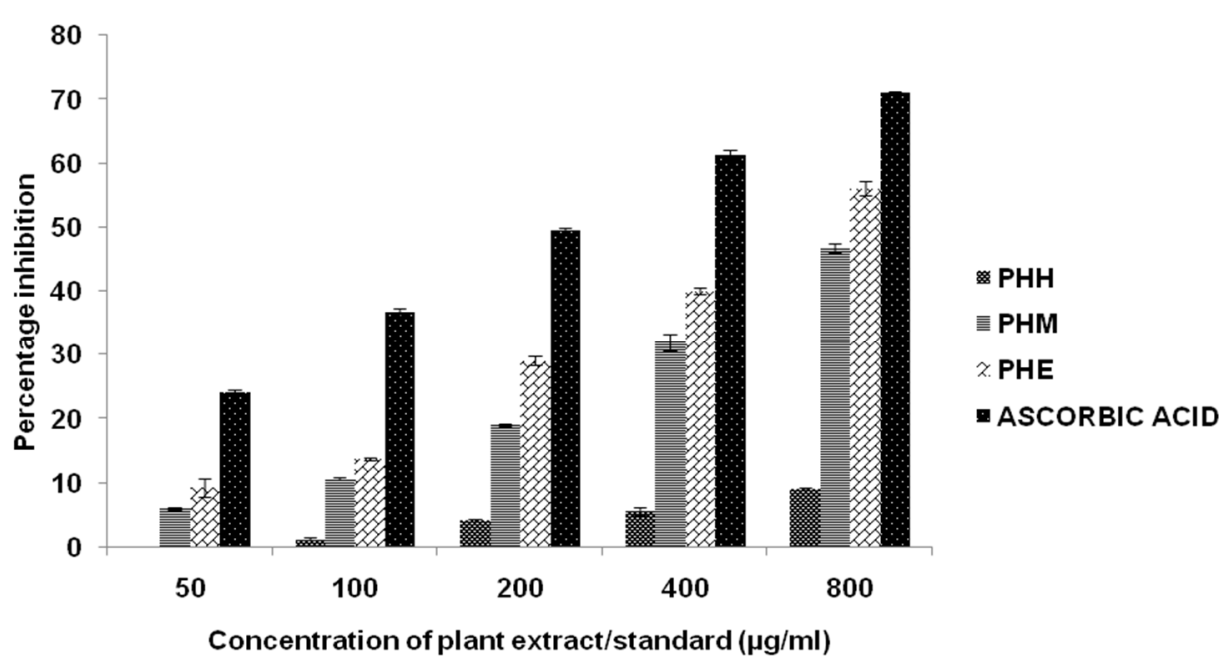

Fig. 4: Inhibition of lipid peroxidation by the different extracts of Pyrrosia heterophylla in vitro. PHH-hexane extract, PHM-methanol extract, PHE-ethyl acetate extract. Values are represented as mean $\pm S E M, n=3$

Ferric ions reducing antioxidant power assay (FRAP)

In the reducing power assay, the antioxidant compounds which are capable of donating an electron reduce the $\mathrm{Fe}^{3+}$ to $\mathrm{Fe}^{2+}$. Amount of $\mathrm{Fe}^{2+}$ complex formed can be monitored by measuring the absorbance of Prussian blue coloured ferric Ferro cyanide, $\left(\mathrm{Fe}_{4}\left[\mathrm{Fe}(\mathrm{CN})_{6}\right]_{3}\right)$, at $700 \mathrm{~nm}$. Higher absorbance means the greater activity of the extracts. The highest reducing power was exhibited by PHE, with an absorbance of $1.75 \pm 0.05$ at $700 \mathrm{~nm}$ for $800 \mu \mathrm{g} / \mathrm{ml}$ concentration (fig. 5). Maximum absorbance values of PHM and PHH were 0.74 and 0.07 respectively. PHH had very low reducing power. Previous studies have proved that plant extracts containing different phytochemicals display antioxidant activity through their reductive capacity in a $\mathrm{Fe}^{3+}-\mathrm{Fe}^{2+}$ system $[30,31]$. Electron donation capacity is considered as an important mechanism of antioxidant activity of phenolic compounds [32]. The phenolic compounds in the extracts PHE and PHM could be responsible for the reductive potential of these extracts.

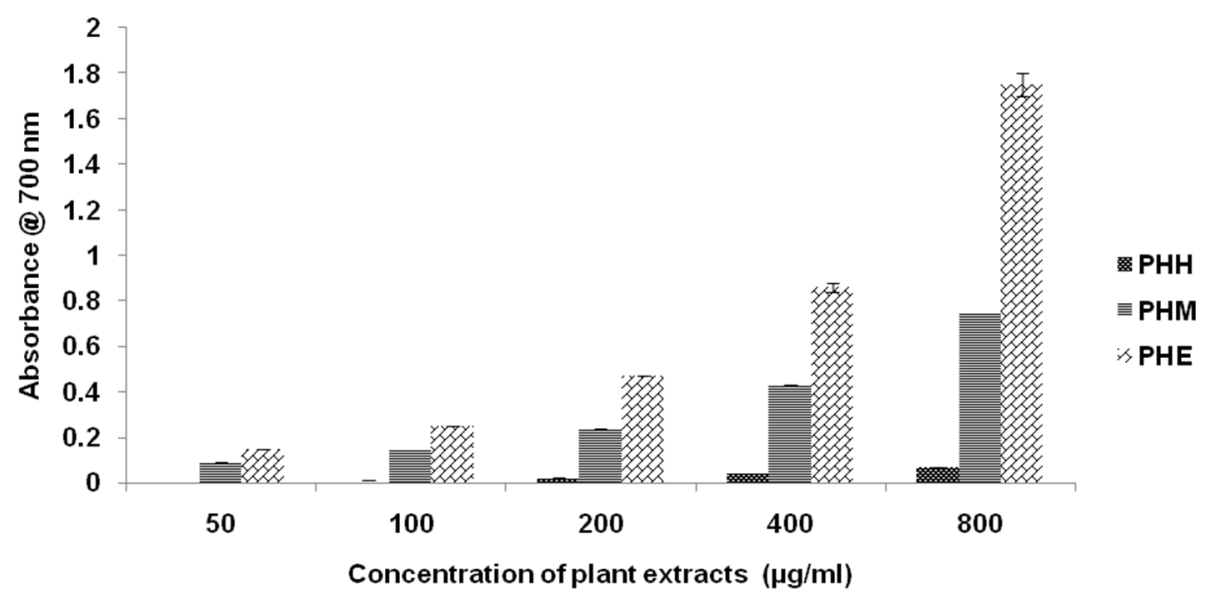

Fig. 5: Ferric reducing antioxidant power of the different extracts of Pyrrosia heterophylla. PHH-hexane extract, PHM-methanol extract, PHE-ethyl acetate extract. Values are represented as mean $\pm S E M, n=3$

Table 1: The effective concentration of Pyrrosia heterophylla extracts to get $50 \%$ inhibition $\left(\mathrm{EC}_{50}\right)$ in different antioxidant protocols

\begin{tabular}{lllll}
\hline Plant extract & EC $_{\mathbf{5 0}}(\boldsymbol{\mu g} / \mathbf{m l})$ & & \\
\cline { 2 - 5 } & DPPH & ABTS & Hydroxyl & Lipid peroxidation inhibition \\
\hline PHH & $1782.65 \pm 3.63$ & $1816.90 \pm 2.10$ & $2191.28 \pm 3.34$ & $1872.00 \pm 3.21$ \\
PHE & $197.24 \pm 2.32$ & $388.80 \pm 1.62$ & $353.88 \pm 1.10$ & $652.54 \pm 2.34$ \\
PHM & $475.47 \pm 2.75$ & $749.82 \pm 2.34$ & $565.96 \pm 3.50$ & $790.63 \pm 3.16$ \\
Standard & $112.63 \pm 4.38$ & $163.46 \pm 0.40$ & $176.32 \pm 2.25$ & $332.15 \pm 2.51$ \\
\hline
\end{tabular}

PHH-hexane extract, PHM-methanol extract, PHE-ethyl acetate extract. Values are represented as mean \pm SEM of three replicates.

\section{Total antioxidant capacity and phenolic content}

The total antioxidant activity and phenolic content of different extracts are given in Table.2. Ethyl acetate extract had the highest phenolic content followed by PHM. Hexane extract had very low phenolic content compared to the other two extracts. The total antioxidant activity was also the highest for ethyl acetate extract. PHM had lesser activity compared to PHE. PHH exhibited very low 
antioxidant activity. The phosphomolybdenum assay measured the ability of the extracts to reduce Phosphate-molybdenum (VI) to Phosphate-molybdenum (V). This assay helped to understand the total antioxidant potential of the extracts quantitatively. Results were similar to many previous studies where the extracts with higher phenolic content exhibited more antioxidant activity [33]. The highest antioxidant activity of the PHE could be correlated with its high phenolic content in the present study.

Table 2: Total phenolic content and antioxidant activity of Pyrrosia heterophylla extracts

\begin{tabular}{lll}
\hline Extract & Total antioxidant activity (mg of AAE/g of extract) & Total phenolic content (mg of GAE/g of extract) \\
\hline PHH & $13.76 \pm 3.95$ & $37.50 \pm 2.18$ \\
PHE & $538.33 \pm 3.51$ & $207.22 \pm 1.95$ \\
PHM & $283.33 \pm 7.57$ & $197.92 \pm 2.00$ \\
\hline
\end{tabular}

$\mathrm{AAE}=$ ascorbic acid equivalents; GAE = gallic acid equivalents. Values are represented as mean $\pm \mathrm{SEM}$ of three replicates .

\section{Antimicrobial activity}

From the results of the antimicrobial assay (table 3), all the extracts were found to inhibit the growth of the tested microorganisms. Hexane extract exhibited the maximum inhibition against E. coli $(18.67 \pm 1.15 \mathrm{~mm}), S$. aureus $(11.67 \pm 0.58 \mathrm{~mm})$ and $A$. niger $(19.33 \pm 1.15 \mathrm{~mm})$. Ethyl acetate extract possessed higher inhibition against $S$. mutans $(17 \pm 1.73 \mathrm{~mm})$ and $C$. albicans $(23.67 \pm 0.58 \mathrm{~mm})$ compared to other extracts. The methanol extract was the most effective against $K$. pneumonia $(24.67 \pm 0.58 \mathrm{~mm})$ and $P$. aeruginosa $(21.00 \pm 0 \mathrm{~mm}) . \mathrm{MIC}_{50}$ value of PHH against E. coli $(26.7 \pm 0.01 \mu \mathrm{g} / \mathrm{ml})$ was found to be the lowest (table 4); thus it exhibited the highest antimicrobial activity. Among the other species, except for $S$. aureus, the lowest $\mathrm{MIC}_{50}$ value was exhibited by the hexane extract. MIC values of all the extracts against the tested microbes were found to be below $40 \mu \mathrm{g} / \mathrm{ml}$. Hence all these extracts of $P$. heterophylla is proved to exhibit good antimicrobial activity. The microorganisms tested in the present study are human pathogenic species known to cause different diseases in man. Microorganisms developing resistance to traditional antibiotics is the major challenge in the treatment of diseases. Plant extracts possess a number of phytochemicals, and the presence of many active compounds in the plant extracts may reduce the risk of developing resistance [34]. If the MIC value of a plant extract is less than $100 \mu \mathrm{g} / \mathrm{ml}$, it is considered to have good antimicrobial activity [35]. For all the extracts tested in the present study, the $\mathrm{MIC}_{50}$ values were found to be below $100 \mu \mathrm{g} / \mathrm{ml}$. From the results, we could conclude that all the extracts of Pyrrosia heterophylla possess good antimicrobial effect.

Table 3: Antimicrobial activity of Pyrrosia heterophylla extracts tested by well diffusion assay (at concentration $100 \mu \mathrm{g} / \mathrm{ml}$ )

\begin{tabular}{|c|c|c|c|c|c|c|c|}
\hline \multirow[t]{2}{*}{ Plant extract } & \multicolumn{7}{|c|}{ Zone of inhibition (mm) } \\
\hline & K. pneumoniae & P. aeruginosa & S. mutans & E. coli & S. aureus & C. albicans & A. niger \\
\hline PHH & $22.67 \pm 0.58$ & $20.67 \pm 0.58$ & $14.00 \pm 0$ & $18.67 \pm 1.15$ & $11.67 \pm 0.58$ & $21.33 \pm 1.53$ & $19.33 \pm 1.15$ \\
\hline PHE & $15.00 \pm 1.00$ & $15.67 \pm 0.58$ & $17 \pm 1.73$ & $8.33 \pm 1.53$ & $8.67 \pm 1.15$ & $23.67 \pm 0.58$ & $18.33 \pm 1.53$ \\
\hline PHM & $24.67 \pm 0.58$ & $21.00 \pm 0$ & $15.33 \pm 0.58$ & $10.67 \pm 0.58$ & $7.67 \pm 1.15$ & $20.00 \pm 0$ & $17.67 \pm 0.58$ \\
\hline Standard & $35.67 \pm 1.15$ & $26.33 \pm 1.53$ & $28.67 \pm 1.53$ & $23.33 \pm 1.15$ & $31.67 \pm 1.53$ & $38.67 \pm 1.53$ & $28.33 \pm 1.53$ \\
\hline
\end{tabular}

Values are represented as mean \pm SEM of three replicates.

Table 4: Minimum inhibitory concentration $\left(\mathrm{MIC}_{50}\right)$ values $(\mu \mathrm{g} / \mathrm{ml})$ of Pyrrosia heterophylla extracts against the tested microorganisms

\begin{tabular}{|c|c|c|c|c|c|c|c|}
\hline Extract & E. coli & S. aureus & K. pneumoniae & P. aeruginosa & S. mutans & C. albicans & A. niger \\
\hline PHH & $26.7 \pm 0.01$ & $35.64 \pm 0.03$ & $31.05 \pm 0.02$ & $33.20 \pm 0.04$ & $28.66 \pm 0.01$ & $28.56 \pm 0.04$ & $29.15 \pm 0.01$ \\
\hline PHE & $32.37 \pm 0.11$ & $31.87 \pm 0.07$ & $39.84 \pm 0.15$ & $37.16 \pm 0.08$ & $29.06 \pm 0.03$ & $33.73 \pm 0.13$ & $38.76 \pm 0.12$ \\
\hline PHM & $31.51 \pm 0.02$ & $34.63 \pm 0.09$ & $33.39 \pm 0.03$ & $34.00 \pm 0.01$ & $31.96 \pm 0.02$ & $31.48 \pm 0.01$ & $33.17 \pm 0.01$ \\
\hline
\end{tabular}

Values are represented as mean \pm SEM of three replicates.

\section{CONCLUSION}

The results of the present study indicate the antioxidant potential of the ethyl acetate and methanol extracts of Pyrrosia heterophylla. These two extracts exhibited significant antioxidant, free radical scavenging and reducing abilities. This can be correlated to their high phenolic contents. Moreover, they exhibited a potent inhibitory effect on lipid peroxidation. The highest level of protection was exhibited by PHE. The study also establishes antimicrobial properties of this plant species as evidenced by antimicrobial screening with tested human pathogenic microorganisms. Plant extracts with potential antioxidant activities are important in terms of their possible disease prevention and curing effects in vivo. Further studies on the biological activities of these extracts will help to understand their efficacy in vivo. Pyrrosia heterophylla extracts can be considered as potential agents that can be used in the management and treatment of oxidative stress-induced diseases.

\section{ACKNOWLEDGEMENT}

The authors are thankful to The Principal, Mar Ivanios College, Thiruvananthapuram, Kerala, India for providing the necessary facilities to carry out the research work. The first author acknowledges the financial support from the University Grants Commission in the form of Teacher Fellowship (No. FIP/12 th plan/KLKE013 TF 08 dt 29/10/2013).

\section{CONFLICT OF INTERESTS}

Authors declare no conflict of interests

\section{REFERENCES}

1. Halliwell B, Gutteridge JMC. Free radicals in biology and medicine. 4th ed. Oxford University Press; UK; 2007.

2. Valko M, Izakovic M, Mazur M, Rhodes CJ, Telser J. Role of oxygen radicals in DNA damage and cancer incidence. Mol Cell Biochem 2004;266:37-56.

3. Valko M, Leibfritz D, MoncolaJ, Cronin MD, Mazur M, Telser J. Free radicals and antioxidants in normal physiological functions and human disease. Rev Int J Biochem Cell Biol 2007;39:44-84.

4. Halliwell B. Biochemistry of oxidative stress. Biochem Soc Trans 2007;35:1147-50. 
5. Genestra M. Oxyl radicals, redox-sensitive signalling cascades and antioxidants. Rev Cell Signal 2007;19:1807-19.

6. Yoshikawa T, Toyokuni S, Yamamoto Y, Naito Y. editors. Free radicals in Chemistry, Biology and Medicine. London: OICA International; 2000.

7. Pham-Huy LA, He H, Pham-Huy C. Free radicals, antioxidants in disease and health. Int J Biomed Sci 2008;4:89-96.

8. Schuler P. Natural antioxidants exploited commercially. In: Hudson BJF. editor. Food Antioxidants. London: Elsevier; 1990. p. $99-170$.

9. Abdallah EM. An overview of the effects of antibiotics and medicinal plant extracts on the human microflora. Nova J Med Biol Sci 2016;5:1-6.

10. Rathee D, Rathee P, Rathee S, Rathee D. Phytochemical screening and antimicrobial activity of Picrorrhiza kurroa, a traditional Indian plant used to treat chronic diarrhea. Arab J Chem 2016;9:S1307-13.

11. Caius JF. The medicinal and poisonous ferns of India. J Bombay Nat His Soc 1935;38:341-61.

12. George M, Josekumar VS. In vitro cytotoxicity screening, phytochemical profile and heavy metal analysis of different extracts of Acrostichum heterophyllum L. Indian J Nat Prod Resour 2016;7:19-24.

13. Blois MS. Antioxidant determination by the use of a stable free radical. Nature 1958;181:1199-200.

14. Delgado-Andrade C, Rufián-Henares JA, Morales FJ. Assessing the antioxidant activity of melanoidin from coffee brews by different antioxidant methods. J Agric Food Chem 2005;53:7832-6.

15. Gutteridge JM, Halliwell B. The deoxyribose assay: an assay both for 'free' hydroxyl radical and for site-specific hydroxyl radical production. Biochem J 1988;253:932-3.

16. Ohkawa H, Ohishi N, Yagi K. Assay for lipid peroxides in animal tissues by thiobarbituric acid reaction. Anal Biochem 1979;95:351-8.

17. Oyaizu M. Studies on the product of browning reactionantioxidative activities of products of browning reaction prepared from glucosamine. Japan J Nutr 1986;44:307-15.

18. Kannan RPR, Arumugam R, Anantharaman P. In vitro antioxidant activities of ethanol extract from Enhalus acoroides (L. F.) Royle. Asian Pac J Trop Med 2010;3:898-901.

19. Singleton VL, Rossi JA Jr. Colorimetry of total phenolics with phosphomolybdic-phosphotungstic acid reagents. Am J Enol Viticul 1965;16:144-58.

20. National Committee for Clinical Laboratory Standards. Reference method for broth dilution antifungal susceptibility testing of yeasts. Approved standard Document M27-A. National Committee for Clinical Laboratory Standards, Wayne, Pa; 1997.

21. Bondet V, Brand-Williams W, Berset C. Kinetics and mechanisms of antioxidant activity using the DPPH free radical method. LWT-Food Sci Technol 1997;30:609-15.

22. Aliev G, Palacios HH, Lipsitt AE, Fischbach K, Lamb BT, Obrenovich ME, et al. Nitric oxide as an initiator of brain lesions during the development of Alzheimer disease. Neurotox Res 2009;16:293-305.

23. Leopoldini M, Marino T, Russo N, Toscano M. Antioxidant properties of phenolic compounds: $\mathrm{H}$-atom versus electron transfer mechanism. J Phys Chem 2004;108:4916-22.

24. Miller NJ, Rice-Evans CA. Factors influencing the antioxidant activity determined by the ABTS-radical cation assay. Free Radical Res 1997;26:195-9.

25. Aliaga C, Lissi EA. The reaction of 2,2'-azinobis (3-ethylbenzothiazoline-6-sulfonic acid (ABTS) derived radicals with hydroperoxides. Kinetics and mechanism. Int J Chem Kinet 1998;30:565-70.

26. Valko M, Leibfritz D, Moncola J, Cronin MTD, Mazura M, Telser J. Free radicals and antioxidants in normal physiological functions and human disease. Int $\mathrm{J}$ Biochem Cell Biol 2007;39:44-84.

27. Farhan H, Malli F, Rammal H, Hijazi A, Bassal A, Ajouz N, et al. Phytochemical screening and antioxidant activity of Lebanese Eryngium creticum L. Asian Pac J Trop Biomed 2012;2:S1217-20.

28. Bajpai VK, Agrawal P. Studies on phytochemicals, antioxidant, free radical scavenging and lipid peroxidation inhibitory effects of Trachyspermum ammi seeds. Indian J Pharm Educ Res 2015;49:58-65.

29. Halliwell B, Gutteridge JM. Oxygen toxicity, oxygen radicals, transition metals and disease. Biochem J 1984;219:1-14.

30. Gogoi N, Gogoi A, Neog B. Free radical scavenging activities of Garcinia xanthochymus hook. f. and Garcinia lanceaefolia roxb. using various in vitro assay models. Asian J Pharm Clin Res 2015;8:138-41.

31. Usha B, Pushpalatha KC. In vitro antioxidant activity and phytochemical screening of leaf extracts of Grewia heterotricha Mast. Int J Curr Pharma Res 2016;8:68-72.

32. Brewer MS. Natural antioxidants: sources, compounds, mechanisms of action, and potential applications. Compr Rev Food Sci Food Saf 2011;10:221-47.

33. Iwansyah AC, Damanik RM, Kustiyah L, Hanafi M. Relationship between antioxidant properties and nutritional composition of some galactopoietic herbs used in Indonesia: a comparative study. Int J Pharm Pharm Sci 2016;8:236-43.

34. Guerrini A, Sacchetti G, Muzzoli M, Rueda GM, Medici A, Besco E. Composition of the volatile fraction of Ocotea bofo Kunth (Lauraceae) calyces by GC-MS and NMR fingerprinting and its antimicrobial and antioxidant activity. J Agric Food Chem 2006;54:7778-88.

35. Dabur R, Gupta A, Mandal TK, Singh DD, Vivek B, Gurav AM, et al. Antimicrobial activity of some Indian medicinal plants. Afr J Tradit Complementary Altern Med 2007;4:313-8.

\section{How to cite this article}

- Meera George, Leenamma Joseph, VS Josekumar. Antioxidant, anti-lipid peroxidative and antimicrobial properties of the epiphytic fern, Pyrrosia heterophylla (L.) M. G. price. Int J Pharm Pharm Sci 2017;9(4):87-93. 